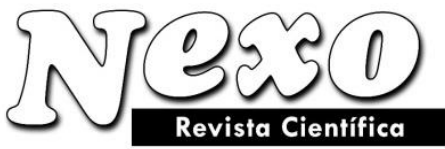

ISSN-E 1995-9516

Universidad Nacional de Ingeniería COPYRIGHT @ (UNI). TODOS LOS DERECHOS RESERVADOS

http://revistas.uni.edu.ni/index.php/Nexo

https://doi.org/10.5377/nexo.v34i06.13135

\title{
The effect of remote work on the successful development of engineering company
}

\section{El efecto del trabajo remoto en el exitoso desarrollo de la empresa de ingeniería}

\author{
Anna Evgenievna Gorokhova ${ }^{1, *}$, Luiza Tagirovna Eskerkhanova ${ }^{2}$, Andrey Nikolaevich Shishkin $^{3}$ \\ ${ }^{1}$ Moscow Polytechnic University. Moscow, Russian Federation. \\ ${ }^{2}$ Chechen State University named after Akhmat Abdulkhamidovich Kadyrov. Grozny, Russia \\ ${ }^{3}$ Tula State Lev Tolstoy Pedagogical University. Tula, Russia. \\ *Corresponding author E-mail: gorokhovaa.e@ mail.ru
}

(recibido/received: 22-septiembre-2021; aceptado/accepted: 02-diciembre-2021)

\begin{abstract}
The purpose of the present study is to identify the main advantages and problems of remote work for both employers and employees, and possible ways to solve them. The article shows a significant number of studies dealt with non-standard forms of labor organization, clarifies the essence of remote work, and examines the main aspects for its effective organization. The main advantages and problems of remote work for employers and employees, as well as possible ways to solve them, are identified based on an expert survey involving 36 experts. According to the conducted study, it can be concluded that the acceleration of scientific and technological progress and adverse epidemiological conditions contribute to the spread of remote work worldwide. This phenomenon has two aspects. On the one hand, remote work, firstly, reduces the unemployment rate and improves the image of the company; secondly, offers flexible working hours; thirdly, protects/retains customers and saves time/transport costs. On the other hand, remote work is associated with the difficulty in maintaining efficiency and teamwork at a high level; secondly, it restricts communication, makes it impossible to perform certain tasks at home; and thirdly, remote work leads to insufficient physical activity, causes difficulties with integration into the corporate culture, etc.
\end{abstract}

Keywords: COVID-19 pandemic; Remote employment; Remote work; Employer; Employee.

\section{RESUMEN}

El objetivo del presente estudio es identificar las principales ventajas y problemas del trabajo a distancia tanto para empleadores como para empleados, y las posibles formas de solucionarlos. El artículo muestra un número significativo de estudios sobre formas atípicas de organización laboral, aclara la esencia del trabajo a distancia y examina los principales aspectos para su eficaz organización. Las principales ventajas y problemas del trabajo a distancia para empleadores y empleados, así como las posibles formas de resolverlos, se identifican a partir de una encuesta de expertos en la que participaron 36 expertos. Según el estudio realizado, se puede concluir que la aceleración del progreso científico y tecnológico y las condiciones epidemiológicas adversas contribuyen a la expansión del trabajo a distancia en todo el mundo. Este fenómeno tiene dos aspectos. Por un lado, el trabajo a distancia, en primer lugar, reduce la tasa de paro y mejora la imagen de la empresa; en segundo lugar, ofrece horarios de trabajo flexibles; en tercer lugar, 
protege / retiene a los clientes y ahorra tiempo / costes de transporte. Por otro lado, el trabajo a distancia se asocia a la dificultad de mantener la eficiencia y el trabajo en equipo a un alto nivel; en segundo lugar, restringe la comunicación, imposibilita la realización de determinadas tareas en el hogar; y en tercer lugar, el trabajo a distancia conduce a una actividad física insuficiente, dificulta la integración en la cultura corporativa, etc.

Palabras claves: Pandemia de COVID-19; Empleo a distancia; Trabajo remoto; Empleador; Empleado.

\section{INTRODUCTION}

The socio-economic problems caused by the COVID-19 coronavirus pandemic actualize the need to find new forms of organizing the work of personnel. Humanity is forced to transform its life, adapt to new requirements, and learn to quickly adapt to atypical realities. Mitigating the negative manifestations of this problem could be achieved through the wider implementation of remote work. This increases the relevance of studying the remote form of work, and its impact on the macro- and micro-economic indicators of enterprises and organizations; as well as prevention and elimination of possible negative aspects.

The urgency of this problem is noted in numerous studies, according to which approximately $68 \%$ of the global workforce, including $81 \%$ of employers, live in those countries where recommendations or requirements for closing enterprises currently apply (Davies, 2021).

It should be noted that remote work has become more common in the last decade. By the time of the COVID19 pandemic, researchers estimate that only $8 \%$ of the world's workforce, or roughly 260 million people, were permanently working at home. For EU countries, the proportion of remote workers aged 15-64 was only slightly more than 5\% in 2019 and has remained so for the past decade. At that, in the USA, the number of employees working home-based has grown by $115 \%$ and reached $2.8 \%$ of all employed Americans (3.9 million people) over the past 10 years (Delanoeije et al., 2019).

\section{LITERATURE REVIEW}

A fairly large number of scientific studies directly or indirectly analyze certain socio-economic aspects of non-standard forms of labor organization (Felstead and Henseke, 2017; Fonner and Roloff, 2010; Goncharov et al., 2020). The majority of publications concern the socio-economic consequences of various forms of labor organization such as remote work, flexible working hours, etc. (Dudin et al., 2019; Martin and MacDonnell, 2012; Poddubnaya et al., 2021; Vasilyeva and Shuraleva, 2015). It is also worth noting that there are different opinions on the definition of concepts such as remote work (Table 1).

Table 1. Definition of the concept of remote work.

\begin{tabular}{|c|c|}
\hline Source & Definition \\
\hline Prokushev & and Remote work is a non-standard form of employment, based on flexible social and labor relations \\
\hline Prokusheva, 20 & $\begin{array}{l}\text { between the employee and the employer, which takes place in a virtual environment using } \\
\text { information and communication technologies }\end{array}$ \\
\hline Zakalyuzhnaya, & $\begin{array}{l}\text {, } 2015 \text { Remote work is the work of an organization's employee outside the office using electronic } \\
\text { communication means }\end{array}$ \\
\hline $\begin{array}{l}\text { Greer and } \mathrm{F} \\
2014\end{array}$ & $\begin{array}{l}\text { Payne, The nature of remote work is that using information and communication technologies the work } \\
\text { is moved away from the premises of the employer (this concerns at least } 20 \% \text { of the working } \\
\text { time) }\end{array}$ \\
\hline $\begin{array}{l}\text { Tremblay } \\
\text { Thomsin, } 2012\end{array}$ & $\begin{array}{l}\text { and Remote work is based on the removal of the employee from the traditional workplace, flexible } \\
\text { working hours, the use of information and telecommunication technologies as the basis of } \\
\text { institutional relations }\end{array}$ \\
\hline
\end{tabular}


Kelliher

Anderson, 2010

Wheatley, 2012 and Remote work is flexible ability to work in an area located outside the usual workplace

Remote work a kind of labor activity that is carried out in a location remote from the central office, which excludes the face-to-face communication of the employee with management and colleagues

To one degree or another, the issue of remote work has been raised in the works of scientists in various fields of knowledge. In particular, E.V. Chichina (2004) considered methodological and practical problems of the development of non-standard flexible forms of employment, determined the specifics of the manifestation of non-standard forms of employment resulted from the spread of the latest information and communication technologies, and justified institutional approaches to the regulation of non-standard flexible types of employment in the national labor market. T. Hartig, C. Kylin and G. Johansson (2007) identified the current trends in the emergence of new forms of employment that occur under the impact of innovative and globalizing processes, and transformational processes in the field of employment that affect the social and labor sphere, change the structure and content of social and labor relations.

Studies (Belzunegui-Eraso and Erro-Garces, 2020; Dudin et al., 2020; Golden and Gajendran, 2019; Ushakov et al., 2018) indicate that during the pandemic, many office-based workers switched to remote work. At that, many of the employees (Delanoeije and Verbruggen, 2020; Wang et al., 2021) and employers are ready to continue working remotely or in a mixed-mode (Reuschke and Felstead, 2020). Researchers have identified both the main advantages of remote work (the ability to work from anywhere (Gallacher and Hossain, 2020), flexible working hours (Carnevale and Hatak, 2020), saving transport costs (Dubey and Tripathi, 2020)) and disadvantages (unauthorized access to corporate information, and data leakage (Kazekami, 2020)).

Despite numerous studies and useful suggestions, the need to re-examine the phenomenon of remote work and consider in more detail its advantages and problems still is an urgent issue, as well as the relevance of remote work in the context of the pandemic still ongoing in many countries.

The research hypothesis: the spread of remote work worldwide is characterized by two opposite aspects, creating both advantages and problems for employers and employees.

Research objectives: 1 . To determine the main advantages of remote work during quarantine measures; 2. To identify the main problems of remote work and possible ways to solve them.

The article consists of an introduction, a literature review, research methods, research results, discussion, and conclusion.

\section{METHODS}

\subsection{Research design}

To solve the tasks set in the study, a qualitative analysis of modern trends in the remote work organization was carried out, and the following set of theoretical and empirical research methods was determined:

- analysis, synthesis, comparison, and generalization methods, used in the study of scientific literature, sociological research on the state of the problem under study;

- the expert survey method, employed to determine the advantages and problems of remote work with their subsequent characteristics. 
The experts were asked to respond voluntarily to the questions of the semi-formalized questionnaire. Based on the expert survey method, the main advantages and problems of remote work for both employers and employees are identified, as well as possible ways to solve them.

\subsection{Research tools and procedure}

The survey involved 36 experts from managers and employees of engineering and commercial companies whose personnel were forced to switch to remote work during the period of quarantine measures.

All participants were warned about the purpose of the survey and the planned publication of the results of the study in a generalized form.

\subsection{Statistical analysis}

In the course of mathematical processing of the research results, the percentage of expert mentions of the advantages and problems of remote work was determined for their subsequent ranking, as well as the ways of their possible solutions.

The ranking of the entire set of remote work advantages/problems mentioned by experts was based on their ordering by each of the experts according to their decreasing preference. At that, each of the advantages/problems were assessed by the rank (number) under which they were listed in the sequence. The final rank of advantage/problem was the arithmetic mean of all the expert ranks in the expert sample.

With an acceptable probability of expert evaluation error $(5 \%)$, the required number of experts $(\mathrm{N}=0.5 \cdot(3 / \mathrm{b}$ $+5)$, where $\mathrm{b}$ is the acceptable probability of expert evaluation error as a percentage/100) was 33 people.

\section{RESULTS}

During the survey, it turned out that the shift of company employees to remote work, especially during quarantine measures, has its advantages both for the organization the employees (Table 2).

Table 2. The main advantages of remote work during quarantine measures.

\begin{tabular}{|c|c|c|}
\hline Advantages & $\% *$ & Rank \\
\hline \multicolumn{3}{|l|}{ For the employer and the organization: } \\
\hline $\begin{array}{l}\text { 1. Switching to remote employment, instead of, for example, providing leave without pay or } \\
\text { even dismissing part of employees, significantly improves the image of the company and the } \\
\text { loyal attitude of employees }\end{array}$ & 83.3 & 1 \\
\hline 2. Protecting and retaining customers & 80.6 & 2 \\
\hline $\begin{array}{l}\text { 3. Taking care of the employees' health and, as a result, reducing cases of illness, increasing } \\
\text { the capacity for labor, and, consequently, the efficiency of personnel }\end{array}$ & 77.8 & 3 \\
\hline 4. Remote teams can be created in different compositions and sizes & 69.4 & 4 \\
\hline 5. Reducing the number of labor misconduct (unauthorized leave, etc.); & 66.7 & 5 \\
\hline $\begin{array}{l}\text { 7. Remote work saves the costs of maintaining the office and the employee's workplace (in } \\
\text { particular, utilities, computer equipment maintenance costs), and the like }\end{array}$ & 61.1 & 6 \\
\hline \multicolumn{3}{|l|}{ For the employee: } \\
\hline 1. Ability to organize a flexible work schedule & 86.1 & 1 \\
\hline 2. Saving time and transport costs for home-to-office trips & 80.6 & 2 \\
\hline 3. Opportunity to combine the performance of professional and domestic duties & 72.2 & 3 \\
\hline 4. Ability not to comply with some corporate requirements (for example, dress code), etc. & 69.4 & 4 \\
\hline 5. Significantly reducing conflicts with the team and management & 52.8 & 5 \\
\hline
\end{tabular}


At the first glance, when switching to remote work, there should be no problems in the teamwork, since teams are already formed, and regardless of where they work, they should continue to work well. However, as experts note, in practice remote working intercommunications can differ significantly from those in the office, causing certain problems (Table 3).

Table 3. The main problems associated with remote work and possible ways to solve them.

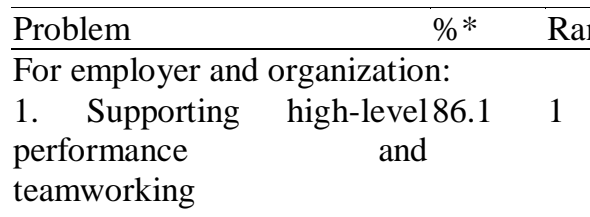

2. Remote monitoring of 75.0 work, managing the work-life balance, integrating these two aspects

For employee:

1. Overwork (continuous83.3 1 working hours, holding too many online meetings)

2. Insufficient physical72.2 2 activity (immobility during work)

3. Certain social isolation69.4 3 (feeling isolated, insufficient group communication with colleagues)

4. Time problems due to66.7 4 working in different time zones

5. Difficulties with61.1 5 integration into the corporate culture and being "visible" to management
A possible solution to the problem

Creating common goals, interest in working together

Promoting transparency of actions at all levels and demonstrating benefits for employees

Training both managers and employees in communication and coordination methods in the virtual environment

Promoting trust among all employees

2 Creating a centralized communication system

Using special platforms to organize and ordering the work of the team; structuring the information and discussions of the team using thematic channels (for example, Trello, Asana, Twist, etc.)

Checking and providing systematic recommendations on all issues of the team (the frequency depends on the specific situation, but preferably it should be done daily).

Setting corporate standards for working from home and providing assistance to remote employees in balancing their professional and personal life

Setting the correct working schedule Organizing workspace

Avoiding multitasking: setting a particular goal for a certain period and focusing on achieving it

Avoiding any distractions

Allocating special time in working schedule for systematic physical training

Performing special exercises during work that do not require immobility and increased attention; trying to stand when possible, rather than sit

Getting acquainted with all the team members

Participating in group meetings to create a social connection between employees

$\mathrm{Be}$ a reliable and responsive team member

Using a convenient communication platform for remote teams to communicate

Using an integrated calendar where all team members can set their own specific availability time

If possible, using special programs for asynchronous communication (for example, Doist), which allow compensating for the rejection of real-time conversations

Participating in shaping the corporate culture

Participating in important team meetings and events to feel like a part of the team

Using various technologies (for example, video conferencing) to communicate with colleagues

Performing set tasks on time 


\section{DISCUSSION}

Available sociological studies (Golden and Gajendran, 2019) indicate that during the COVID-19 pandemic, more than $35 \%$ of workers shifted to work from home. The pandemic has triggered a long-overdue stage of technological and social experiments that significantly affect the future fate of office workers.

Therefore, today, employers and governments around the world are trying to determine how relevant remote work will be after the end of the pandemic. At that, the opinions of employees and business owners somewhat differ.

It should be noted that studies (Belzunegui-Eraso and Erro-Garces, 2020; Delanoeije and Verbruggen, 2020; Wang et al., 2021) prove that the majority of the surveyed employees and some employers are ready to continue working remotely or in a mixed-mode (several days working in the office, and several days home-based). Although most of them admit that at first, they had to get used to remote work. Thus, according to the study (Belzunegui-Eraso and Erro-Garces, 2020), 82\% of the surveyed office employees in 25 countries of the world expressed a desire to continue working from home one or two days a week after the complete abolition of quarantine measures. Another study came to similar conclusions, according to which six out of ten French people who have worked remotely want to continue working from home regularly or in individual cases (Delanoeije and Verbruggen, 2020). The results of a study conducted by representatives of the Japanese Labor Productivity Center have shown that more than $60 \%$ of employees surveyed would like to continue working remotely after the end of the pandemic (Wang et al., 2021).

Part employers around the world have also evaluated the remote form of work, and plan to use it after the end of the pandemic. For example, according to the results of the study (Reuschke and Felstead, 2020), 54\% of German companies that took part in the survey plan to use remote work more often after the end of the pandemic than before. At that, $75 \%$ of the survey participants noted that in recent months they have recommended their employees to work from home.

The results of sociological studies (Carnevale and Hatak, 2020; Gallacher and Hossain, 2020) also allowed determining the main advantages and disadvantages of remote employment. Thus, those who liked the home-based office, among the advantages, in addition to not having to spend time and money on transport, mention the ability to work from anywhere, to spend more time with the family, inclusiveness (more opportunities for people with special needs), flexibility in terms of working schedule, i.e. the ability to choose when to work during the day, as well as increased autonomy, motivation, and work performance, more comfortable working conditions, and reduced stress.

According to the results of an American study (Dubey and Tripathi, 2020), during the coronavirus pandemic, Americans saved $\$ 91$ billion. Thus, everyone who used to spend money on the way to the office and back saved an average of $\$ 2$ thousand on transport since mid-March. In addition, Americans save about \$ 183 million a day by reducing the number of trips to the gas station or the car-care center. As for business owners, they consider a reduction in the cost of renting an office and its maintenance the biggest advantage in remote work, as well as the ability to hire employees from other cities to work remotely, and greater work efficiency outside the usual format.

According to the interviewed experts, positive achievements should be used in the future, however without rejecting the negative aspects peculiar to remote work. Indeed, remote work has its drawbacks and can be a 
source of discomfort. For example, some employees feel more isolated, take fewer breaks, and complain that they have to work more, disrupt a work-life balance.

Among the negative aspects, experts named certain restrictions in the organization's activities, in particular, problems with documents, and the lack of the ability to visually track the work of employees. In addition, according to experts, the transition to remote work increases technological risks - from the leakage of confidential information to the loss of data and the availability of systems, since not all companies can provide employees with proper equipment, and employees are forced to work with home computers.

Thus, almost 40 Japanese companies that transferred some employees to remote work came across with unauthorized access to their servers, which led to a data leak. Among other things, the attackers gained access to the passwords of employees required for remote work. Among the suffered companies are those belonging to the pharmaceutical, energy, and automotive industries (Hitachi Chemical, Sumitomo Forestry, and others). Representatives of the government Cyber Security Center believe that over time, these companies may face not only the subsequent loss of confidential data but also the risk of infection of corporate servers with viruses (Kazekami, 2020).

However, the administrations of many Japanese corporations that have implemented a remote work format for their employees to ensure business continuity while maintaining people's health, have also concluded that even after the complete victory over the pandemic, remote work should not be abandoned. This will become one of the elements of the restructuring aimed at improving personnel management efficiency. Thus, the management of the Hitachi corporation reported that despite the lifting of the quarantine its employees will visit the office only once or twice a week. In addition, the company provides for payments to each employee of three thousand yen per month to compensate for the costs associated with home-based work. The Japanese company Fujitsu also decided to permanently reduce the area of leased office space by $50 \%$ over the next three years, and transfer 80 thousand employees to remote operation. At the same time, the company's employees are provided with a payment of five thousand yen (about \$ 46) per month. It is expected that such encouragement will allow employees to organize the home workplace in the best possible way and quickly get used to the new format of performance of official duties (Kazekami, 2020).

Although experts predict an increase in the number of remote workers after the quarantine, they are confident that this practice will not become widespread. At the same time, the global companies that consider remote work as the most promising option for the development of labor relations in the context of the COVID-19 pandemic and other possible threats to the life and health of their employees, include leading technology giants such as Google, Microsoft, Apple, Samsung, etc. For example, Facebook is going to become a promising company in the field of organizing remote work. Facebook is considering remote work as part of its long-term strategy and plans to move up to $50 \%$ of its employees to remote work. The implementation of these plans will take from five to ten years. The social network is already looking for a director of remote work, who should develop a long-term remote work plan and lead the team during this period. Today, the social network employs 48 thousand people worldwide. The American company Twitter also allowed its employees to work at home after completion of the quarantine (globally almost five thousand people work currently remotely). At that, the company's management increased the allowance for working from home to $\$$ one thousand for all employees (Dingel and Neiman, 2020).

At that, some experts - company executives believe that a completely remote mode of operation is doomed to failure. They believe that after the pandemic, many companies will switch to a hybrid operation mode, namely, working in the office one or two weeks a month, or several days a week, because making important decisions or creative work requires personal presence. Only those who need to take care of young children will be able to work fully from home. 
The interviewed experts are convinced that we are not talking about mass transfer to remote work in the near future. As one of the interviewed experts notes, "employers mostly want to see a person in the workplace, therefore the absolute majority plans to return to the standard mode of work". A similar opinion was expressed by another expert, noting that "the remote work format will only be expanding in the future, while the ideal work option will be a mixed version, or for example, remote work can become an incentive for those with better performance characteristics".

\section{CONCLUSION}

In the current context, the development of distance employment becomes possible for many reasons. First, at the present stage of high-tech development, the cost of computers and telecommunications is decreasing, while their power is increasing. Secondly, the latest technical means and services of open electronic networks, including the Internet, are spreading quite quickly. Third, the motivation of employers and employees to explore new opportunities to achieve success in a business or an individual project is gradually increasing.

The reality is that the interest in remote work among organizations and employees is growing, especially with the rapidly growing changes in remote communication technologies. The processes of digitalization, contemporary information technologies, and the computer experience of employees provide them with the opportunity to solve work tasks remotely. Consequently, one can expect an increase in the number of remote jobs in various organizations. At the same time, there are several problems in the management of personnel working in remote access mode. To make effective use of their capabilities and potential, more time should be devoted to the development of such employees.

Further scientific research can be associated primarily with improving the organizational support of remote work to minimize risks and threats to various aspects of social and labor relations.

\section{REFERENCES}

Belzunegui-Eraso, A. and Erro-Garces, A. (2020). Telework in the context of the COVID-19 crisis. Sustainability, 12, 3662.

Carnevale, J. B. and Hatak, I. (2020). Employee adjustment and well-being in the era of COVID-19: Implications for human resource management. Journal of Business Research, 116, 183-187.

Chichina, E. V. (2004). Certain non-standard forms of employment: the legal aspect. Minsk, Belarus: Right and Economy, $142 \mathrm{p}$.

Davies, A. (2021). COVID-19, and ICT-supported remote working: opportunities for rural economies. World, 2, 139-152.

Delanoeije, J. and Verbruggen, M. (2020). Between-person and within-person effects of telework: A quasifield experiment. European Journal of Work and Organizational Psychology, 29 (6), 795-808.

Delanoeije, J., Verbruggen, M. and Germeys, L. (2019). Boundary role transitions: a day-to-day approach to explain the effects of home-based telework on work-to home conflict and home-to-work conflict. Human Relations, 72 (12), 1843-1868.

Dingel, J. I. and Neiman, B. (2020). How many jobs can be done at home? Journal of Public Economics, 189, 104235. http://dx.doi.org/10.1016/j.jpubeco.2020.104235 
Dubey, A. D. and Tripathi, S. (2020). Analyzing the sentiments towards work-from-home experience during COVID-19 pandemic. The Journal of Innovation Management, 8, 13-19.

Dudin, M. N., Bezbakh, V. V., Galkina, M. V., Rusakova, E. P. and Zinkovsky, S. B. (2019). Stimulating innovation activity in enterprises within the metallurgical sector: the Russian and international experience. TEM Journal, 8 (4), 1366-1370.

Dudin, M. N., Shakhov, O. F., Ivashchenko, N. P. and Shakhova, M. S. (2020). Development of entrepreneurial competencies in the economy (evidence from digital entrepreneurship). Revista Inclusiones, 7 (Especial Enero-Marzo), 54-68

Felstead, A. and Henseke, G. (2017). Assessing the growth of remote working and its consequences for effort, well-being, and work-life balance. New Technology, Work and Employment, 32 (1), 195-212. http://dx.doi.org/10.1111/ntwe.12097

Fonner, K. L. and Roloff, M. E. (2010). Why teleworkers are more satisfied with their jobs than are officebased workers: When less contact is beneficial. Journal of Applied Communication Research, 38 (4), 336361.

Gallacher, G., and Hossain, I. (2020). Remote work and employment dynamics under COVID-19: evidence from Canada. Canada Public Policy, 46, 44-54.

Golden, T. D. and Gajendran, R. S. (2019). Unpacking the role of a telecommuter's job in their performance: examining job complexity, problem solving, interdependence, and social support. Journal of Business and Psychology, 34 (1), 55-69.

Goncharov, V. V., Stepanova, D. I., Kovalev, D. V., Kovaleva, T. A. and Batyrshina, A. R. (2020). Blended learning perspectives for students (university experience under constraints due to COVID-19 pandemic). Revista Inclusiones, 7 (Especial), 288-300.

Greer, T. W. and Payne, S. C. (2014). Overcoming telework challenges: outcomes of successful telework strategies. Psychologist-Manager Journal (American Psychological Association), 17 (2), 87-111.

Hartig, T., Kylin, C., and Johansson, G. (2007). The telework tradeoff: Stress mitigation vs. constrained restoration. Applied Psychology, 56 (2), 231-253.

Kazekami, S. (2020). Mechanisms to improve labor productivity by performing telework. Telecommunications Policy, 44 (2), 101868. http://dx.doi.org/10.1016/j.telpol.2019.101868

Kelliher, C. and Anderson, D. (2010). Doing more with less? Flexible working practices and the intensification of work. Human Relations, 63 (1), 83-106.

Martin, B. H. and MacDonnell, R. (2012). Is telework effective for organizations? A meta-analysis of empirical research on perceptions of telework and organizational outcomes. Management Research Review, 35 (7), 602-616.

Poddubnaya, T. N., Zadneprovskaya, E. L. Voevodina, S. S., Ilyinova, N. A., Khatit, F. R. and Panina, E. A. (2021). Distance learning experience in the context of globalization of education. Propositos $y$ Representaciones, 9 (1), e985. 
Prokushev, E. F. and Prokusheva, A. P. (2014). Remote employment as a factor in the development of labor resources. Bulletin of the Belgorod University of Cooperation, Economics, and Law, 1 (49), 92-97.

Reuschke, D. and Felstead, D. (2020). Changing workplace geographies in the COVID-19 crisis. Dialogues in Human Geography, 10, 208-212.

Tremblay, D. G. and Thomsin, L. (2012). Telework and mobile working: Analysis of its benefits and drawbacks. International Journal of Work Innovation, 1 (1), 100-113.

Ushakov, D., Vinichenko, M. and Frolova, E. (2018). Environmental capital in national economy stimulation: limitations of rationality. Advanced Science Letters, 24 (9), 6290-6292.

Vasilyeva, Yu. V. and Shuraleva, S. V. (2015). Remote work: new opportunities for Russian business. Economics and Entrepreneurship, 9 (2), 961-965.

Wang, B., Liu, Y., Qian, J. and Parker, S. K. (2021). Achieving effective remote working during the COVID-19 pandemic: A work design perspective. Applied Psychology, 70 (1), 16-59.

Wheatley, D. (2012). Good to be home? Time-use and satisfaction levels among home-based teleworkers. New Technology, Work and Employment, 27 (3), 224-241.

Zakalyuzhnaya, N. V. (2015). Remote work, and similar legal relations. Right. Journal of the Higher School of Economics, 2, 76-91. 